\title{
BMJ Open Does endometriosis affect professional life? A matched case-control study in Switzerland, Germany and Austria
}

\author{
Marita Lina Sperschneider, ${ }^{1,2}$ Michael P Hengartner, ${ }^{3}$ Alexandra Kohl-Schwartz, ${ }^{1,4}$ \\ Kirsten Geraedts, ${ }^{1}$ Martina Rauchfuss, ${ }^{5}$ Monika Martina Woelfler, ${ }^{6}$ Felix Haeberlin, ${ }^{7}$ \\ Stephanie von Orelli, ${ }^{8}$ Markus Eberhard, ${ }^{2}$ Franziska Maurer, ${ }^{9}$ Bruno Imthurn, ${ }^{1}$ \\ Patrick Imesch, ${ }^{10}$ Brigitte Leeners ${ }^{1}$
}

To cite: Sperschneider ML, Hengartner MP, Kohl-Schwartz A, et al. Does endometriosis affect professional life? A matched case-control study in Switzerland, Germany and Austria. BMJ Open 2019;9:e019570. doi:10.1136/ bmjopen-2017-019570

- Prepublication history for this paper is available online. To view these files, please visit the journal online (http://dx.doi org/10.1136/bmjopen-2017019570).

Received 14 September 2017 Revised 30 July 2018 Accepted 1 August 2018

Check for updates

(C) Author(s) (or their employer(s)) 2019. Re-use permitted under CC BY-NC. No commercial re-use. See rights and permissions. Published by BMJ.

For numbered affiliations see end of article.

Correspondence to

Dr Brigitte Leeners;

brigitte.leeners@usz.ch

\section{ABSTRACT}

Objectives Endometriosis is a gynaecological disease most commonly causing severe and chronic pelvic pain as well as an impaired quality of life. The aim of this study was to investigate if and how endometriosis affects choices regarding professional life as well as the quality of daily working life.

Design, setting and participants In the context of a multicentre case-control study, we collected data from 505 women with surgically/histologically confirmed diagnosis of endometriosis and 505 matched controls. Study participants were recruited prospectively in hospitals and doctors' practices in Switzerland, Germany and Austria. Using a detailed questionnaire, the study investigated work-life and career choices of study participants.

Main outcome measures Associations between endometriosis/disease symptoms and limitations in career development as well as ability to work.

Results Women with endometriosis were less often able to work in their desired profession than women from the control group (adjusted OR=1.84, 95\% Cl: 1.15 to 2.94 , $R^{2}=0.029, p=0.001$ ) and they had to take health-related limitations into consideration in their career decisions to a significantly higher degree than women in the control group $\left(\mathrm{OR}=4.79,95 \% \mathrm{Cl}\right.$ : 2.30 to $9.96, \mathrm{R}^{2}=0.063$, $p<0.001)$. Among women with endometriosis, chronic pain was significantly associated with increased sick leave $\left(\mathrm{OR}=3.52,95 \% \mathrm{Cl}: 2.02\right.$ to $\left.6.13, \mathrm{R}^{2}=0.072, \mathrm{p}<0.001\right)$ as well as with loss of productivity at work $(\mathrm{OR}=3.08,95 \% \mathrm{Cl}$ : 2.11 to $4.50, R^{2}=0.087, p<0.001$ ).

Conclusions Endometriosis is associated with impairment of professional life, in particular with regard to career choices. Further research to develop strategies to support endometriosis-affected women in realising professional opportunities is recommended.

Trial registration number NCT02511626; Pre-results.

\section{INTRODUCTION}

Endometriosis is a gynaecological disease defined by the presence of endometrium-like tissue outside the uterine cavity. ${ }^{1}$ The prevalence of the disease among women of reproductive age is estimated to be between $8 \%$

\section{Strengths and limitations of this study}

- The study presents one of the largest samples and is one of the first studies providing a matched control group to investigate the association between endometriosis and professional activity.

- Recruitment of study participants in university hospitals, district hospitals and private doctors' practices ensures a representative sample.

- Validation of diagnosis and stage of endometriosis provide high data quality.

- The use of a self-reported questionnaire may have caused recall bias.

- Due to lack of investigation of diseases or symptoms that may also have influenced professional life in the control group, results may be underestimated.

and $10 \% .{ }^{23}$ However, as reliable diagnosis of endometriosis can only be made by surgery and endometriosis can be asymptomatic, an unknown number of affected women might remain undiagnosed and so its prevalence might be far higher. ${ }^{4}$

Women suffering from endometriosis experience most commonly one or more of the following symptoms: chronic pelvic pain, severe dysmenorrhea, deep dyspareunia, pain during defecation/urination, loin pain, irregular bleeding, constipation/diarrhoea, as well as reduced fertility and chronic fatigue. ${ }^{5-7}$ Numerous and severe symptoms, chronicity of the disease, ${ }^{8}$ side effects of therapies ${ }^{9}$ as well as diagnostic delays ${ }^{1011}$ significantly affect women's overall quality of life, including professional performance, and place high demands on the treating physicians. ${ }^{12-14}$ For most patients, available treatment options, such as analgesics, various hormonal therapies and radical laparoscopy, ${ }^{1}$ are often not curative and are associated with significant side effects. ${ }^{12} 15$ 
Consequently, disease symptoms, especially endometriosis-related pain and fatigue, may disturb the development and realisation of long-term goals such as a professional career $^{16}$ and may make it difficult to meet the demands of a job. About $40 \%$ of women with endometriosis report impaired career growth due to endometriosis, ${ }^{13}$ and about $50 \%$ experience a decreased ability to work due to their chronic disease. ${ }^{12} 17$ Differentiated knowledge on the nature of such limitations and, in particular, on how adjustments to professional life can be made to improve professional performance is currently lacking.

The quality of working life is a major aspect in quality of life overall, ${ }^{18}$ which in turn is the most important predictor of total cost of disease. ${ }^{19}$ About $66 \%$ to $75 \%$ of the total costs of endometriosis arise from reduced ability to work and not from direct costs of treatment. ${ }^{1920}$ Being able to work in a desired occupation may not only have a strong impact on a woman's financial situation and on the perception of and attitude towards daily work, but can also be an important health factor. For example, unsatisfactory work and limited possibilities for change are associated with increased levels of headache, fatigue and depressed mood. ${ }^{21}$

Frequent sick leave and reduced work productivity can put affected women under observation by superiors and under greater pressure to deliver full performance. ${ }^{22} 23$ The rather intimate and gender-specific nature of the most common endometriosis symptoms tends to make affected women feel embarrassed. ${ }^{24}$ Consequently, some women may avoid discussing endometriosis-related problems with superiors and colleagues, particularly if the superiors and colleagues are male. ${ }^{24}{ }^{25}$ Due to the invisibility of their disease, women can be easily perceived as malingerers. ${ }^{24}$ Therefore, medical professionals need to know how the symptoms of endometriosis can affect daily working life and professional development, notably because endometriosis-affected women repeatedly underline their wish for comprehensive information ${ }^{24} 2627$ and advice in managing their disease in daily life, ${ }^{26} 27$ instead of isolated treatment of endometriosis symptoms. ${ }^{242627} \mathrm{~A}$ better understanding of endometriosis and its impacts on any aspect of life, including professional activity, not only by medical professionals but also in society and politics would help affected women and their families to reduce the negative consequences of the disease. However, research on quantitative and qualitative impairment of working life as the necessary background for offering adequate support and interventions is scarce and relies mainly on interview-based studies with small samples of affected women ${ }^{23} 24$; there is only one other study that uses a control group. ${ }^{14}$ In addition, work-related stress in women diagnosed with endometriosis has not been investigated yet.

Therefore, it was the aim of the present study to evaluate parameters of working life of a larger number of endometriosis-affected women, and compare findings with those of a matched control group. We investigated (i) perceived health-related limitations in career decisions; (ii) quality of the current work situation; and (iii) the association between endometriosis-related disease symptoms and work performance.

\section{MATERIAL AND METHODS Study design}

The study is designed as a multicentre case-control study. The main outcome measures are health limitations in career choice as well as quality and stability of the current work situation. Secondary outcome measures investigate the impact of different symptoms as well as localisation of endometriosis on sick leave and loss of productivity. The study has been conducted and reported applying the criteria of the Strengthening the Reporting of Observational Studies in Epidemiology (STROBE) statement. ${ }^{28}$

\section{Recruitment}

The recruitment of study participants is shown in figure 1 . To detect a $10 \%$ difference between cases and controls with an alpha of 0.05 and a power of 0.8 , a sample size of 387 participants in each group is needed. With the inclusion of 505 participants in both groups, we consequently reached a very high power, for example 99.1 for the detection of differences in desired profession or 99.7 for health-related limitations in career choice. Study participants were recruited prospectively for a research project on the quality of life including professional activity in endometriosis-affected women compared with control women. ${ }^{7929-31}$ Recruitment took place between January 2010 and December 2015 at the following hospitals and associated doctors' offices in Switzerland, Germany and Austria: the University Hospital Zurich, the Triemli Hospital Zurich, the district hospitals in Schaffhausen, Solothurn, St. Gallen, Winterthur, Baden and Walenstadt, the Charité Berlin, the Vivantes Humboldt Hospital Berlin, the Albertinen Hospital Hamburg, the University Hospital Aachen and the University Hospital Graz. In doctors' offices one or several gynaecologists work together in a medical unit; district hospitals offer tertiary care associated with a university.

Healthcare professionals carried out the recruitment of all study participants via the direct approach. The study was explained to the respondents and information about the voluntary nature of participation as well as anonymity of data in reports and publications was provided. Participants were given all documents and a return envelope.

Inclusion criteria: All study participants had to be between 18 and 50 years old. For the case group, women with surgically and histologically diagnosed endometriosis were included irrespective of stage, location of lesions and severity and profile of symptoms. Only data sets with at least $80 \%$ of answers for main and secondary outcome measures were included.

Exclusion criteria: Women were excluded in cases of current pregnancy or linguistic, mental or psychological impairments that might affect their ability to understand and to complete the questionnaire. 
Women diagnosed

with Endometriosis

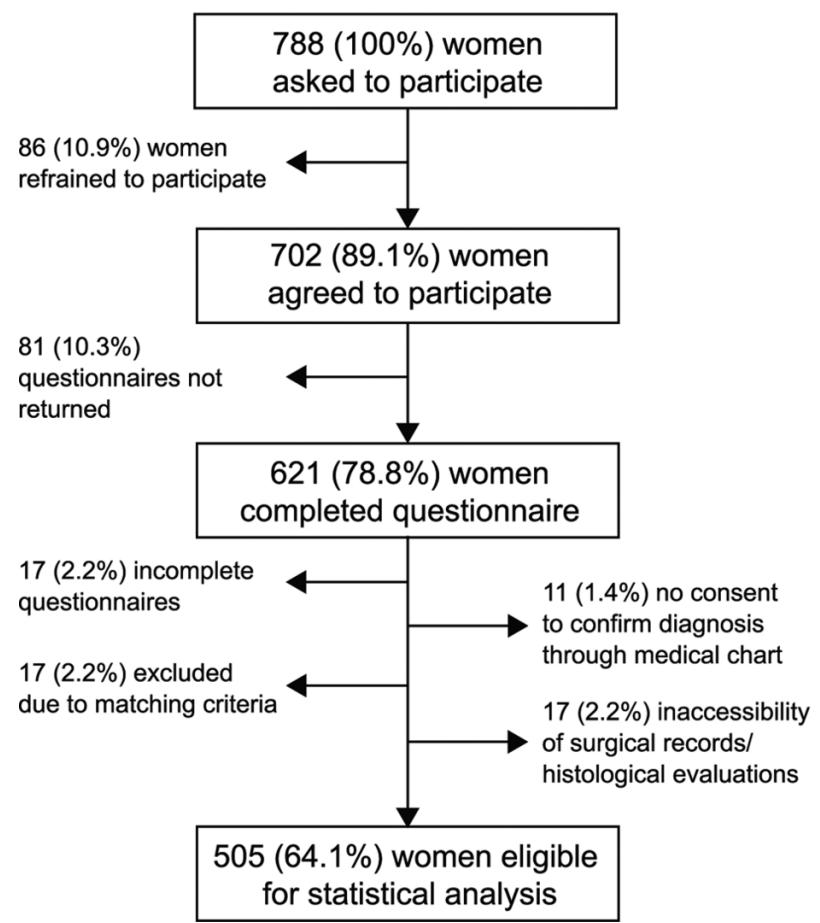

Control women *

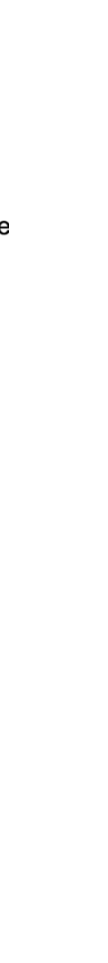

1411 (100\%) women

asked to participate

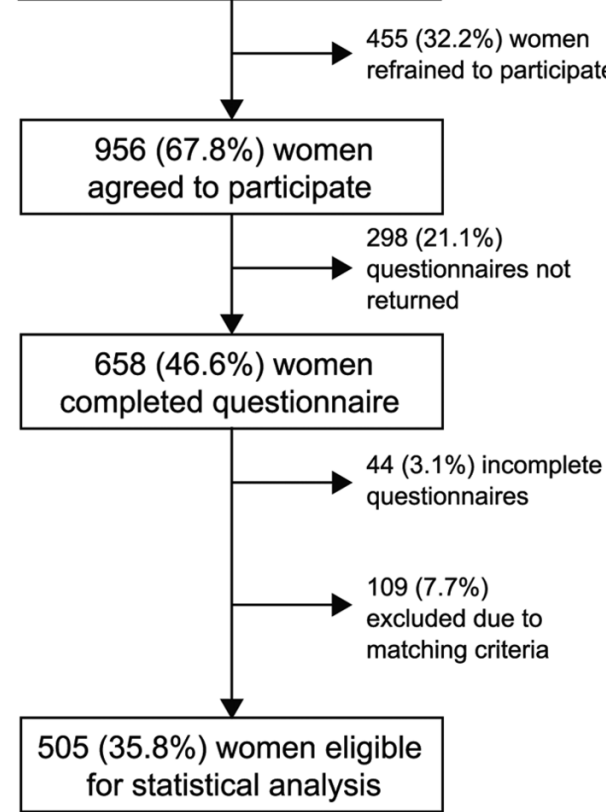

for statistical analysis

Figure 1 Recruitment of study participants. *Women presenting for routine gynaecological care or benign gynaecological surgery.

The most frequent reasons reported for not participating were lack of time and the intimate nature of some of the questions. To maximise the return rate, women were reminded to complete and return the questionnaire after 1 month and after 3 months.

A smaller segment of the case group ( $n=74,66$ of which could be included in the final analysis $(13.1 \%$ of total case group)) was recruited through different self-help groups for endometriosis patients (in Germany only). Education levels and family incomes in this cohort are similar to those in the main group. However, the women in this cohort were significantly older than those in the hospital group ( $42.45 \pm 6.03$ vs $37.02 \pm 7.21$ years, $\mathrm{p}<0.001$ ), showed a longer time since primary diagnosis $(82.11 \pm 8.36$ vs $37.20 \pm 44.00$ months, $\mathrm{p}<0.001)$ and presented at the time of the study a significantly higher stage of disease $(\mathrm{p}=0.013)$.

Control women were recruited during regular annual or biennial gynaecological consultations at hospitals' out-patient clinics or in private offices, as part of standard healthcare in the three countries where recruitment took place. In addition, women during hospital stays because of temporary mild benign gynaecological problems other than endometriosis were invited to participate in the study. Each control woman was matched to a woman diagnosed with endometriosis for age ( \pm 3 years) and ethnic background, that is, Caucasian or not (pair matching).

\section{Questionnaire}

The structured self-administered questionnaire for the total study on quality of life contained 390 questions for all participants and 90 additional specific questions for women diagnosed with endometriosis. It is structured in different chapters, one of which is professional life. Further chapters covered questions regarding lifestyle; general well-being; general, gynaecological, and medical history; childhood experiences; sexuality and partnership. Women diagnosed with endometriosis were additionally asked to provide detailed information on the diagnosis and treatment of endometriosis, symptoms of endometriosis, sick leave and productivity loss specifically due to endometriosis. Wherever possible we used internationally validated questionnaires. Modified versions of the Brief Pain Inventory ${ }^{32}$ and the Pain Disability Index ${ }^{33} 34$ served to evaluate pain. For several questions about professional life as for occupation, sick leave and productivity loss, we used similar reporting methods the Work Productivity and Activity Impairment Questionnaire (WPAI) ${ }^{35}$ suggests, but extended the time period of reporting from only 7 days in the WPAI to 4 weeks and 1 year. Level of education was measured with defined categories following the recommendation to use meaningful benchmarks of educational attainment rather than a continuous scale in years. ${ }^{36}$ In order to capture the professional situation of women diagnosed with endometriosis as close to reality as possible, a interdisciplinary research team including 
specialists for minimally invasive endometriosis surgery, for gynaecological endocrinology and for gynaeco-psychosomatic medicine added their clinical experience and evaluated systematically what they had learnt from individual patients. On this background, specific questions like on working despite pain or on using overtime or holidays to compensate for sick leave were added. The first version of our questions on professional activity was then revised by the governing body of the German selfhelp groups in order to map the questions to the situations reported by women with endometriosis and to avoid using questions that do not correctly depict the specific situation in the context of endometriosis.

The analysis presented in this paper was based on answers to the following questions asked to the case as well as to the control group: nationality (German, Swiss, Austrian, other (with the possibility of entering nationality)), age (years), marital status (married, cohabiting, single), highest achieved education level (lower school education, high school education, apprenticeship, university degree, no formal education, other), current own monthly net income (six choices for responses ranging from none to $>2500$ Euros for participants in Germany and Austria and from none to $>6000$ Swiss francs for participants in Switzerland) and number of pregnancies of more than 24 weeks of gestation. Women were asked to report their levels of current employment (full-time, part-time, full-time housekeeping, student, registered as unemployed) and whether they currently worked in their desired profession (yes, no). The current place of employment was not asked but only on the profession: eg, for a woman who always wanted to be a teacher, is she now able to work as a teacher? They were asked how they perceived their level of qualification for the currently held job (overqualified, about right, underqualified), length of professional experience ( $<5$ years, $6-10$ years and $>10$ years), years working with the current employer ( $<1$ year, $1-5$ years, $6-10$ years, $>10$ years), the subjectively perceived influence of health-related limitations on career choice (not at all, little, medium, strongly, exclusively) and perceived current level of stress on the job (scale from $0=$ none to $10=$ verystrong).

The analysis presented in this paper further used the following questions asked only to women diagnosed with endometriosis: Amount of time since first symptoms of endometriosis were noticed ( $<1$ year ago, 1 year ago, $2-5$ years ago, 6-10 years ago, $>10$ years ago), date of initial diagnosis of endometriosis (month and year), number of surgeries related to endometriosis $(1,2,3,4,5,6$ or more), chronic pain (yes, no), duration of pain $(<1$ year, $1-3$ years, $4-5$ years, $6-10$ years, $11-20$ years, $>20$ years), frequency of pain (a few times per year, a few times per month, several times per week, once a day, several times a day, permanently), cyclic pain (yes, no), psychological symptoms lasting more than 3 months estimated by the study participant to be related to endometriosis, such as depressive mood/anxiety/reduced resilience (yes, no), days worked despite pain during the last month (never, 1-3 days, 4-7 days, 1-2 weeks, 2-4 weeks), frequency of fatigue or exhaustion due to endometriosis (never, rarely, sometimes, often, very often), sick leave due to symptoms of endometriosis (not specified) during the last month (never, 1-3 days, 4-7 days, 1-2 weeks, 2-4 weeks), sick leave due to symptoms of endometriosis in the last year (never, 1-7 days, 1-2 weeks, 2-4 weeks, 4-8 weeks, 8-12 weeks, $>12$ weeks), estimated loss of productivity due to endometriosis when symptoms are at their maximum or at their minimum respectively (no loss, a little, somewhat, high), reduction of work time due to endometriosis (no reduction, reduction of $25 \% / 50 \% / 75 \%$ ) and giving up employment entirely due to endometriosis (yes, no). (Chronic pelvic pain included cyclic as well as noncyclic pelvic pain.)

The study was registered at clinicaltrials.gov, where further details on the complete questionnaire are available.

\section{Verification of diagnosis and stage of endometriosis}

To verify the diagnosis and obtain information about localisation of endometriosis lesions, surgical records as well as the histological diagnosis of each patient and each intervention were collected from medical charts. Stage was classified according to the revised Classification of the American Society for Reproductive Medicine (rASRM) ${ }^{37}$

This study followed the guidelines of the World Medical Association Declaration of Helsinki 1964, updated in October 2013.

\section{Patient and public involvement statement}

Questions for this study were selected in cooperation with endometriosis self-help groups. Other than in the self-help groups, patients were not involved in the recruitment and conduct of the study. All interested study participants receive the publications resulting from the study. Publications are also sent to the governing body of the self-help groups.

\section{Statistical analysis}

Differences in sample characteristics between study groups were computed with either independent sample t-tests for continuous variables or Pearson $\chi 2$ tests for categorical variables. To test associations between study groups and characteristics of professional life, we conducted a series of binomial logistic regression. The study group, that is, women with endometriosis as opposed to controls without endometriosis, was included as the dependent variable. To test the association between symptoms of endometriosis and work outcomes in women with endometriosis, we conducted a series of ordinal logistic regression, entering work outcomes as the dependent variable. The proportion of variance explained based on the study group was indicated by Nagelkerke's pseudo R. ${ }^{2}$ Sample characteristics that differed significantly between study groups were statistically adjusted for by including them simultaneously as covariates. Initially, $\alpha$ was set at $5 \%$, but we applied Bonferroni correction to adjust the significance level $\alpha$ for multiple testing. All analyses were conducted with SPSS version 24 for Windows. 
Table 1 Descriptive statistics and group comparisons

\begin{tabular}{|c|c|c|c|}
\hline & \multirow{2}{*}{$\begin{array}{l}\text { Endometriosis } \\
(n=505)\end{array}$} & \multirow{2}{*}{$\begin{array}{l}\text { Controls } \\
(n=505)\end{array}$} & \multirow{2}{*}{$\begin{array}{l}\text { Group } \\
\text { differences }\end{array}$} \\
\hline & & & \\
\hline \multicolumn{4}{|l|}{ Age } \\
\hline $\begin{array}{l}\text { Mean years } \\
\text { (SD) }\end{array}$ & $37.7(7.3)$ & $37.2(9.1)$ & $\mathrm{p}=0.344^{*}$ \\
\hline \multicolumn{4}{|l|}{ Nationality } \\
\hline Swiss & $n=211(42.2 \%)$ & $\mathrm{n}=285(57.3 \%)$ & $\mathrm{p}<0.001 \dagger$ \\
\hline German & $\mathrm{n}=244(48.8 \%)$ & $\mathrm{n}=161(32.4 \%)$ & \\
\hline Others & $\mathrm{n}=45(9.0 \%)$ & $\mathrm{n}=51(10.3 \%)$ & \\
\hline \multicolumn{4}{|l|}{ Marital status } \\
\hline $\begin{array}{l}\text { Married/ } \\
\text { Cohabiting }\end{array}$ & $n=420(83.3 \%)$ & $\mathrm{n}=397(79.4 \%)$ & $\mathrm{p}=0.109 \dagger$ \\
\hline Single & $\mathrm{n}=84(16.7 \%)$ & $n=103(20.6 \%)$ & \\
\hline \multicolumn{4}{|c|}{ Pregnancies $>24$ weeks } \\
\hline 0 & $\mathrm{n}=331(70.6 \%)$ & $\mathrm{n}=245(50.9 \%)$ & $\mathrm{p}<0.001 \dagger$ \\
\hline 1 & $\mathrm{n}=83(17.7 \%)$ & $\mathrm{n}=80(16.6 \%)$ & \\
\hline$\geq 2$ & $\mathrm{n}=55(11.7 \%)$ & $\mathrm{n}=156(32.4 \%)$ & \\
\hline \multicolumn{4}{|c|}{ Education levelł } \\
\hline Low & $\mathrm{n}=71(14.4 \%)$ & $\mathrm{n}=74(14.7 \%)$ & $\mathrm{p}=0.990 \dagger$ \\
\hline Medium & $\mathrm{n}=245(49.6 \%)$ & $\mathrm{n}=249(49.4 \%)$ & \\
\hline \multicolumn{4}{|c|}{ Paid occupation } \\
\hline High & $n=178(36.0 \%)$ & $\mathrm{n}=181(35.9 \%)$ & $\mathrm{p}=0.016 \dagger$ \\
\hline Full-time & $\mathrm{n}=248(49.8 \%)$ & $\mathrm{n}=206(41.8 \%)$ & \\
\hline Part-time & $\mathrm{n}=176(35.3 \%)$ & $\mathrm{n}=186(37.7 \%)$ & \\
\hline None & $\mathrm{n}=74(14.9 \%)$ & $n=101(20.5 \%)$ & \\
\hline \multicolumn{4}{|c|}{ Occupation among mothers§ only } \\
\hline Full-time & $\mathrm{n}=30(22.1 \%)$ & $\mathrm{n}=57(23.9 \%)$ & $\mathrm{p}=0.120 \dagger$ \\
\hline Part-time & $\mathrm{n}=68(50.0 \%)$ & $\mathrm{n}=136(57.1 \%)$ & \\
\hline None & $\mathrm{n}=38(27.9 \%)$ & $\mathrm{n}=45(18.9 \%)$ & \\
\hline
\end{tabular}

*Independent samples t-test.

†Pearson $\chi^{2}$-test.

¥Scale: Low, ‘no formal education/lower school education';

medium, higher school education/apprenticeship; high,

university degree.

§Women with at least one pregnancy $>24$ weeks.

\section{RESULTS}

\section{Characteristics of study groups and possible confounders}

A comparison of socio-epidemiological parameters between women with endometriosis and control women is presented in table 1. Significant variables, for example, nationality, pregnancies and paid employment, were included as covariates in subsequent analyses on casecontrol effects. Table 2 shows disease characteristics in women with endometriosis.

\section{Parameters of working life}

Parameters of professional activity in women diagnosed with endometriosis and control women are presented in table 3A.

Spearman correlation between professional experience and length of time in the current employment was $\mathrm{r}=0.490(\mathrm{p}<0.001)$.
Table 2 Disease characteristics in women diagnosed with endometriosis

\begin{tabular}{|c|c|c|}
\hline Criteria & $\begin{array}{l}\text { Endometriosis } \\
\text { group (\%) }\end{array}$ & $\mathbf{N}$ \\
\hline \multicolumn{3}{|c|}{ Time since occurrence of first symptoms $(\mathrm{N}=474)$} \\
\hline$<1$ year & 5.49 & 26 \\
\hline 1 year & 5.27 & 25 \\
\hline $2-5$ years & 28.06 & 133 \\
\hline $6-10$ years & 18.99 & 90 \\
\hline$>10$ years & 42.19 & 200 \\
\hline \multicolumn{3}{|c|}{ rASRM stage of endometriosis ( $N=502)$} \\
\hline I & 17.93 & 90 \\
\hline II & 21.12 & 106 \\
\hline III & 28.09 & 141 \\
\hline IV & 32.87 & 165 \\
\hline
\end{tabular}

Number of endometriosis-related surgical interventions $(\mathrm{N}=505)$

\begin{tabular}{|llc}
\hline 1 & 49.31 & 249 \\
\hline 2 & 29.11 & 147 \\
\hline 3 & 7.13 & 36 \\
\hline 4 & 2.77 & 14 \\
\hline 5 & 2.18 & 11 \\
\hline six and more & 2.18 & 11 \\
\hline No information & 7.33 & 37 \\
\hline Mean \pm SD & $1.79 \pm 1.27$ & \\
\hline Douglas obliteration (N=503) & & \\
\hline Yes & 26.6 & 134 \\
\hline No & 73.4 & 369 \\
\hline Involvement of sacrouterine ligaments (N=503) & \\
\hline Yes & 61.4 & 309 \\
\hline No & 38.6 & 194 \\
\hline Involvement of Douglas (N=503) & & \\
\hline Yes & 72.0 & 362 \\
\hline No & 28.0 & 141 \\
\hline Intra-abdominal adhesions (N=504) & \\
\hline Yes & 74.8 & 377 \\
\hline No & 25.2 & 127 \\
\hline Involvement of pelvic wall (N=503) & & \\
\hline Yes & 74.8 & 377 \\
\hline No & 25.2 & 127 \\
\hline Involvement of vaginal fornix or septum rectovaginal (N=503) \\
\hline Yes & 12.7 & 64 \\
\hline No & 87.3 & 439 \\
\hline Endometrioma (N=502) & & \\
\hline Yes & 49.0 & 246 \\
\hline No & 51.0 & 256 \\
\hline Chronic pain (N=500) & & \\
\hline Yes & 58.40 & \\
\hline & & \\
\hline
\end{tabular}




\begin{tabular}{|c|c|c|}
\hline Criteria & $\begin{array}{l}\text { Endometriosis } \\
\text { group (\%) }\end{array}$ & $\mathbf{N}$ \\
\hline No & 41.60 & 208 \\
\hline \multicolumn{3}{|l|}{ Duration of chronic pain } \\
\hline$<1$ year & 3.48 & 10 \\
\hline $1-3$ years & 13.59 & 39 \\
\hline 4-5years & 17.07 & 49 \\
\hline $6-10$ years & 23.34 & 67 \\
\hline 11-20years & 29.27 & 84 \\
\hline$>20$ years & 13.24 & 38 \\
\hline \multicolumn{3}{|l|}{ Frequency of pain } \\
\hline Permanent & 17.06 & 51 \\
\hline Several times per day & 20.40 & 61 \\
\hline Once a day & 1.34 & 4 \\
\hline Several times per week & 26.76 & 80 \\
\hline Few times per month & 31.77 & 95 \\
\hline Few times per year & 2.68 & 8 \\
\hline \multicolumn{3}{|c|}{ Frequency of endometriosis-related fatigue/ exhaustion } \\
\hline Never & 7.39 & 37 \\
\hline Rarely & 15.57 & 78 \\
\hline Sometimes & 26.35 & 132 \\
\hline Often & 28.14 & 141 \\
\hline Very often & 22.55 & 113 \\
\hline \multicolumn{3}{|c|}{ Psychological symptoms due to endometriosis† } \\
\hline Yes & 57.24 & 261 \\
\hline No & 42.76 & 195 \\
\hline
\end{tabular}

${ }^{*}$ Question not answered but diagnosis of endometriosis confirmed with at least one surgical record.

†Depressive mood/anxiety/reduced resilience of more than 3 months.

rASRM, revised Classification of the American Society for Reproductive Medicine.

Associations between endometriosis and work outcomes are presented in table 3B. In the adjusted analysis, all predictor variables plus nationality, occupation and number of pregnancies were included simultaneously as covariates.

The results of the main outcome measures 'health influences on career choice', 'desired profession' and 'professional experience' are highly significant, even if the proportion of variance explained by the last two factors was rather small. Excluding participants who are members of self-help groups did not alter the results.

The intensity of reported health-related limitations in career choice was independent from rASRM stage $(\chi 2$, 16.51, $\mathrm{df}=12, \mathrm{p}=0.169$ ), but associated with the occurrence of chronic pain $(\chi 2,34.39, \mathrm{df}=4, \mathrm{p}<0.001)$ as well as with the frequency of pain $(\chi 2,25.62, \mathrm{df}=8, \mathrm{p}=0.001)$.

Chronic pain was also associated with higher levels of stress at work, even if the mean difference was small (6.61 vs $5.47, \mathrm{SD}=2.39 / 2.49, \mathrm{p}<0.001)$.
Intraoperative findings of spread of endometriosis lesions showed varying associations with health-related limitations in career choice: having endometriosis lesions at the pelvic wall $(\chi 2,11.14, \mathrm{df}=4, \mathrm{p}=0.025)$ or in the sacrouterine ligaments $(\chi 2,13.51, \mathrm{df}=4, \mathrm{p}=0.009)$ was significantly associated with greater limitations in career choice, while such an outcome could not be found for localisation in the vaginal fornix, for an obliteration of Douglas or for adhesions. Higher levels of stress at work were associated with intra-abdominal adhesions (mean 6.36 vs $5.50, \mathrm{SD}=2.46 / 2.48, \mathrm{p}=0.001)$, but not with other intraoperative findings.

\section{Work impairment and compensatory mechanisms}

Asked about the amount of sick leave due to endometriosis during the last month, $78.1 \%$ of the women of the case group reported no sick leave, $8.5 \%$ reported 1 to 3 days, $3.1 \%$ reported 4 to 7 days, $2.0 \%$ reported 1 to 2 weeks and $8.1 \%$ reported 2 to 4 weeks.

Altogether, $13.1 \%$ of endometriosis patients used 1 week or more of overtime or vacation during the last year when they felt too sick to work due to symptoms of endometriosis. Furthermore, $75.5 \%$ of women with endometriosis reported to have gone to work during the previous month in spite of severe pain. Asked about the previous year, $89.2 \%$ of women with endometriosis affirmed to have worked despite pain. Out of the women diagnosed with endometriosis, $89.8 \%$ noted a loss of work productivity due to endometriosis, with $65.1 \%$ reporting strong or very strong limitations when symptoms were severe. On days with minimal endometriosis symptoms, $75.3 \%$ still felt some degree of loss of productivity.

A minority of women with endometriosis reported working part time $(10.3 \%)$ or giving up work entirely $(5.8 \%)$ due to their disease $(n=445)$.

\section{Association of endometriosis-related symptoms with sick leave and productivity loss}

We then examined whether different endometriosis symptoms were related to absenteeism and impaired work productivity (table 4 ).

Corrected for multiple testing, all four predictor variables were significantly associated with sick leave during the previous 4 weeks. The occurrence of chronic pain as well as the frequency of fatigue and concomitant psychological symptoms were associated with significantly higher degrees of perceived productivity loss. Including age and time since diagnosis as potential confounders did not alter the results. Likewise, the factor of different localisations of endometriosis was not associated with sick leave or productivity loss (all $\mathrm{p}>0.05$ ).

\section{DISCUSSION}

Endometriosis is associated with impairment of professional activity: women diagnosed with endometriosis showed a lower likelihood of working in their desired profession and stronger health-related limitations in their career decisions. 
Table 3A Parameters of professional activity in the case and the control group

\begin{tabular}{|c|c|c|c|c|}
\hline Criteria & $\begin{array}{l}\text { Endometriosis } \\
\text { group (\%) }\end{array}$ & $\mathbf{N}$ & $\begin{array}{l}\text { Control } \\
\text { group (\%) }\end{array}$ & $\mathbf{N}$ \\
\hline Own net income per month & & 480 & & 483 \\
\hline No income & 11.25 & 54 & 15.76 & 76 \\
\hline$<3000 \mathrm{CHF}(1000 \mathrm{EUR})^{*}$ & 24.79 & 119 & 28.57 & 138 \\
\hline $3001-6000$ CHF (1001-2500 EUR) ${ }^{\star}$ & 49.17 & 236 & 40.37 & 195 \\
\hline$>6000 \mathrm{CHF}(>2500 \mathrm{EUR})^{*}$ & 14.79 & 71 & 15.32 & 74 \\
\hline Desired profession & & 488 & & 482 \\
\hline Yes & 51.64 & 252 & 64.94 & 313 \\
\hline No & 25.41 & 124 & 14.94 & 72 \\
\hline Partially & 22.95 & 112 & 20.12 & 97 \\
\hline Degree of health-related limitations in career choice & & 486 & & 466 \\
\hline Exclusively & 4.12 & 20 & 0.43 & 2 \\
\hline Strongly & 8.02 & 39 & 3.00 & 14 \\
\hline Somewhat & 10.49 & 51 & 4.94 & 23 \\
\hline Little & 8.23 & 40 & 5.15 & 24 \\
\hline Not at all & 69.14 & 336 & 86.48 & 403 \\
\hline Estimation of adequacy of job qualification & & 459 & & 453 \\
\hline Lower than required & 19.17 & 88 & 17.00 & 77 \\
\hline Same as required & 67.10 & 308 & 74.61 & 338 \\
\hline Higher than required & 13.73 & 63 & 8.39 & 38 \\
\hline Professional experience & & 487 & & 474 \\
\hline$<5$ years & 18.89 & 92 & 32.70 & 155 \\
\hline $5-10$ years & 25.87 & 126 & 21.10 & 100 \\
\hline$>10$ years & 55.24 & 269 & 46.20 & 219 \\
\hline Duration of current employment & & 442 & & 439 \\
\hline$<1$ year & 14.25 & 63 & 20.27 & 89 \\
\hline $1-5$ years & 40.72 & 180 & 41.69 & 183 \\
\hline $6-10$ years & 22.17 & 98 & 18.91 & 83 \\
\hline$>10$ years & 22.85 & 101 & 19.13 & 84 \\
\hline Work-related stress level & & 460 & & 465 \\
\hline No stress & 2.83 & 13 & 1.51 & 7 \\
\hline 1 & 3.26 & 15 & 2.80 & 13 \\
\hline 2 & 4.13 & 19 & 5.16 & 24 \\
\hline 3 & 5.00 & 23 & 10.54 & 49 \\
\hline 4 & 7.39 & 34 & 9.46 & 44 \\
\hline 5 & 13.70 & 63 & 14.624 & 68 \\
\hline 6 & 12.83 & 59 & 14.194 & 66 \\
\hline 7 & 18.70 & 86 & 20.430 & 95 \\
\hline 8 & 16.96 & 78 & 14.624 & 68 \\
\hline 9 & 6.96 & 32 & 2.796 & 13 \\
\hline Very high stress & 8.26 & 38 & 3.871 & 18 \\
\hline
\end{tabular}

*Different income classes in Switzerland and Germany/Austria.

In contrast, they had professional experience of longer durations. All these main outcomes were not reported previously and open new insights into the professional life of women with endometriosis. Endometriosis-associated symptoms and symptom characteristics were moderately related to sick leave and loss of productivity, but in contrast to our expectations, endometriosis was not associated with increased work-related stress levels. 
Table 3В Associations between endometriosis and parameters of professional life including the proportion of variance explained by the disease

\begin{tabular}{|c|c|c|c|c|}
\hline Predictor & Reference category & Unadjusted OR $(95 \% \mathrm{Cl})$ & Adjusted OR $(95 \% \mathrm{Cl})^{*}$ & Pseudo $\mathrm{R}^{2}$ \\
\hline \multirow[t]{3}{*}{ Own income } & 0-3000 CHF & 0.85 (0.58 to 1.24$) ; p=0.396$ & 1.01 (0.56 to 1.83 ); $p=0.975$ & 0.011 \\
\hline & $3001-6000 \mathrm{CHF}$ & 1.26 (0.87 to 1.84$) ; p=0.227$ & 1.23 (0.78 to 1.96$) ; p=0.376$ & \\
\hline & $>6000 \mathrm{CHF}$ & Ref. & Ref. & \\
\hline \multirow[t]{3}{*}{ Desired profession } & No & 2.14 (1.53 to 2.99 ); $p<0.001 \dagger$ & 1.84 (1.15 to 2.94); $\mathrm{p}=0.011$ & 0.029 \\
\hline & Partially & 1.43 (1.04 to 1.97$) ; p=0.026$ & 1.51 (1.02 to 2.23 ); $p=0.038$ & \\
\hline & Yes & Ref. & Ref. & \\
\hline \multirow{3}{*}{$\begin{array}{l}\text { Degree of health- related } \\
\text { limitations in career choice }\end{array}$} & Strongly & 4.42 (2.50 to 7.83$) ; p<0.001 \dagger$ & 4.79 (2.30 to 9.96$) ; p<0.001$ & 0.063 \\
\hline & Moderately & 2.32 (1.59 to 3.40$) ; p<0.001 \dagger$ & 2.61 (1.64 to 4.15$) ; p<0.001$ & \\
\hline & Not at all & Ref. & Ref. & \\
\hline \multirow{3}{*}{$\begin{array}{l}\text { Estimation of adequacy of } \\
\text { job qualification }\end{array}$} & Lower & 1.25 (0.89 to 1.77$) ; p=0.195$ & 0.86 (0.55 to 1.35 ); $p=0.515$ & 0.012 \\
\hline & Higher & 1.82 (1.18 to 2.80$) ; p=0.007 \dagger$ & 1.44 (0.87 to 2.41$) ; p=0.160$ & \\
\hline & Adequate & Ref. & Ref. & \\
\hline \multirow[t]{3}{*}{ Professional experience } & $<5$ years & 0.48 (0.35 to 0.66$) ; p<0.001 \dagger$ & 0.44 (0.28 to 0.71$) ; p=0.001$ & 0.033 \\
\hline & $5-10$ years & 1.03 (0.75 to 1.41$) ; p=0.875$ & 1.02 (0.67 to 1.57 ); $p=0.916$ & \\
\hline & $>10$ years & Ref. & Ref. & \\
\hline \multirow{4}{*}{$\begin{array}{l}\text { Duration of current } \\
\text { employment }\end{array}$} & $<1$ year & 0.59 (0.38 to 0.91$) ; p=0.017$ & 0.84 (0.47 to 1.50$) ; p=0.552$ & 0.011 \\
\hline & $1-5$ years & 0.82 ( 0.57 to 1.17$) ; p=0.268$ & 1.14 (0.71 to 1.84 ); $p=0.584$ & \\
\hline & $6-10$ years & 0.98 (0.65 to 1.48$) ; p=0.931$ & 0.99 (0.60 to 1.65$) ; p=0.975$ & \\
\hline & >10years & Ref. & Ref. & \\
\hline Work-related stress level & one point increase $\neq$ & 1.09 (1.03 to 1.15$) ; p=0.002 \dagger$ & 1.04 (0.97 to 1.12 ); $p=0.230$ & 0.014 \\
\hline
\end{tabular}

${ }^{*}$ Adjusted for all other predictor variables plus nationality, occupation, and number of pregnancies.

$\dagger$ Statistically significant at Bonferroni corrected $\alpha=0.007$.

¥On a scale from 0 (not stress at all) to 10 (extremely severe stress).

Table 4 Association of endometriosis-related symptoms to sick leave and productivity loss in the last month

\begin{tabular}{|c|c|c|c|c|}
\hline \multirow[b]{2}{*}{ Predictor } & \multirow{2}{*}{$\begin{array}{l}\text { Sick leave* } \\
\text { OR }(95 \% \mathrm{Cl})\end{array}$} & \multirow[b]{2}{*}{$\mathbf{R}^{2}$} & \multirow{2}{*}{$\begin{array}{l}\text { Productivity loss } 1 \\
\text { OR }(95 \% \mathrm{Cl})\end{array}$} & \multirow[b]{2}{*}{$\mathbf{R}^{2}$} \\
\hline & & & & \\
\hline \multicolumn{5}{|l|}{ Chronic pain } \\
\hline No & Ref. & & Ref. & \\
\hline \multicolumn{5}{|c|}{ Frequency of pain } \\
\hline$>1$ per week & 1.40 (0.66 to 2.97$) ; p=0.377$ & & 0.76 (0.42 to 1.38$) ; p=0.369$ & \\
\hline$\leq 1$ per week & Ref. & & Ref. & \\
\hline \multicolumn{5}{|c|}{ Frequency of fatigue } \\
\hline Frequently & 3.50 (1.76 to 6.94$) ; p<0.001 \ddagger$ & 0.073 & 3.99 (2.49 to 6.39$) ; p<0.001 \ddagger$ & 0.107 \\
\hline Yes & 3.03 (1.77 to 5.18$) ; p<0.001 \ddagger$ & 0.061 & 2.90 (1.98 to 4.23$) ; p<0.001 \ddagger$ & 0.082 \\
\hline No & Ref. & & Ref. & \\
\hline
\end{tabular}

*Refers to the last 4 weeks; Scale: $1=$ 'never', $2=1-7$ days, $3=>7$ days.

†Refers to current maximal impairments; Scale: 1='not at all, little', 2='moderately, strong', 3='very strong'.

$\ddagger$ Statistically significant at Bonferroni corrected $\alpha=0.01$.

$\S$ Depressive mood/anxiety/reduced resilience of more than 3 months. 
In contrast to remarkable differences regarding parameters of working life, education level did not differ significantly between case and control groups (table 1); this is a result that has been described previously. ${ }^{17}$ Other studies, however, reported serious effects of endometriosis on education level, especially on tertiary formation. ${ }^{12} 24$ These contrasting findings might result from differences in study groups, for example, with regard to the onset of disease symptoms in relation to education, professional training and professional activity. Many studies report an average age of first symptoms between 20 and 29 years,. ${ }^{10} 38-40$ In our study the average age of diagnosis is 33.7 years. Even if many of these women report the onset of endometriosis-related symptoms several years before diagnosis, it is still an age at which most women have completed professional training. As a consequence, the women investigated in such cohorts will not experience a negative impact of endometriosis on their education, because they were still symptom-free at this age. Other authors reported an earlier onset of disease symptoms, ${ }^{41}$ and emphasised that endometriosis in adolescent girls was an underestimated problem. ${ }^{40} 4243$ Consequently, those women, who suffer from endometriosis symptoms already at a young age, might feel limitations due to the disease also early in life, namely already during education.

On the other hand, there might be a higher tolerance for sick leave and impaired energy levels in a school or university setting compared to that in a paid employment.

Health issues are important criteria in career choice, and women diagnosed with endometriosis do work less often in their desired profession. However, women with endometriosis reported a greater length of experience in the current profession (table 3B). Professional experience and the length of time a woman is working with the current employer are highly correlated. These results can be interpreted positively in the sense that women with endometriosis were successful in carefully choosing a long-term profession. On the other hand, women might feel less able to change the professional field and stuck in an undesired profession because of endometriosis.

Several authors reported elevated levels of general ${ }^{44} 45$ as well as emotional ${ }^{21}$ distress in women diagnosed with endometriosis. This first study on work-specific stress in endometriosis affected women produced results in contrast to our expectations. Even though women reported that they sometimes went to work despite endometriosis-associated pain, women with endometriosis did not experience higher work-related stress levels than the control women; but within the group of women with endometriosis, those with chronic pain reported significantly higher work-related stress than those without pain. We investigated women whose initial diagnosis was up to 20 years ago; these women may have meanwhile found an occupation meeting their needs, and superiors and colleagues may have adapted to their sometimes reduced availability for work. Also, the fact that work can be a source of distraction and of self-esteem for individuals suffering from a chronic disease ${ }^{46}$ may offset stressful situations.

According to our results and those of others, ${ }^{41}$ women affected by endometriosis compensate for their health-related restrictions at work by using overtime or vacation for absences as well as by saving energy for work through reduction of leisure time activities.

Despite these personal efforts to adapt to an adverse situation, productivity $\operatorname{loss}^{915}$ and sick leave $\mathrm{e}^{910}$ are relevant issues for many women diagnosed with endometriosis. Average loss of work time per week (absenteeism) due to endometriosis is reported to be between 4.4 and 7.4 hours. ${ }^{13} 14$ In our study, chronic pain, frequency of pain, fatigue and psychological symptoms, such as self-reported depression and anxiety, were significantly-but with modest effect sizes-related to taking more sick leave (table 4). Productivity loss at work due to endometriosis-related symptoms was described to be high or very high-depending on the current severity of symptomsby up to $65 \%$ of women in the present study. Struggles to fulfil normal demands of work might be exacerbated by the side effects of treatment, for example by dizziness from strong pain killers. ${ }^{22}{ }^{23}$ Although, the majority of women affected with endometriosis seemed to be able to compensate for disease-related difficulties at work and to realise successful long-term professional activity, $16.2 \%$ of the women nevertheless reduced their jobs or even gave up work entirely due to endometriosis-related symptoms; this is a situation that has been observed also by others. ${ }^{17}$ Furthermore, a very similar percentage of women with endometriosis and control women worked part time, even though women diagnosed with endometriosis remained childless more often. Such decisions may result from feeling pressured to reduce or quit work when employers know about a chronic disease such as endometriosis. ${ }^{12}{ }^{24}$ More flexible work schedules, a generous policy regarding sick leave, sufficient breaks, adjusted physical demands, the possibility to lie down and the existence of bathrooms nearby are seen to be helpful resources for successful professional performance in women with endometriosis. ${ }^{23} 24$

As for the relationship between rASRM stage and endometriosis-associated symptoms, ${ }^{1}{ }^{3}$ none of the parameters evaluating professional activity showed any significant association with rARSM stage. Testing the association between different intraoperative findings of endometriotic lesions and work outcomes showed inconsistent results. In contrast, most outcome measures were related to the occurrence and frequency of chronic pain; this result is supported by other studies on endometriosis, ${ }^{1419}$ as well as on other chronic pain conditions such as migraine or fibromyalgia. ${ }^{47}{ }^{48}$ Even if the effect size of pain on work in this study is limited, findings support the relevance of pain management for satisfactory work performance. Fatigue, either as a symptom of endometriosis or as a frequent comorbidity, ${ }^{49}$ interfered with professional activity in this as well as in other studies. ${ }^{13}$ 
In summary, it may be that women with endometriosis strive for normality at their work place, even if it is associated with reduced professional flexibility or with giving up the desire for another profession.

This study presents one of the largest samples investigating the association between endometriosis and professional life, and it is one of the very few studies providing a control group. Study participants were recruited in university hospitals, district hospitals and doctors' practices in order to collect a representative sample. The pair matching with regard to age and ethnic background reduced the confounding effect of these factors. A meticulous review of all surgical records by the same investigator (AKS) ensured high data quality with regard to diagnosis and classification of endometriosis. The response rate of $64.1 \%$ in the case group is in the upper level of comparable studies, ${ }^{12} 13$ whereas the response rate of $35.8 \%$ in the control group is comparatively low. We cannot exclude that women with a particularly high work load refrained from study participation; however, such an effect is equally relevant in women diagnosed with endometriosis and in controls. The higher response rate in women with endometriosis supports the fact that such an association does not represent a particular problem for members in this group.

Given the methodology of a self-reported questionnaire answered retrospectively, distortions in the sense of falsely or overly attributing dissatisfaction on the job to endometriosis cannot be excluded. By addressing questions on professional activity either current or in the period just prior to study participation, we tried to reduce recall bias. As we included only patients with a confirmed diagnosis of endometriosis, and as such a confirmation can be provided only by surgery, there may be referral bias. For example, affected but asymptomatic women and symptomatic women who do not have access to or refused surgery might have been excluded, with the first false categorisation might result in overestimation and the second in the underestimation of the results. In contrast, asymptomatic women with endometriosis might have been included in the control group, which would result in underestimation of the results. As we have no differentiated information on symptoms resulting from diseases other than endometriosis, in both groups further confounders might be present; this would also result in underestimation of our findings. Although we recruited women diagnosed with endometriosis independent from their acute symptomatology for example, also those presenting for regular controls, recruitment though hospitals might have resulted in selection of women with more severe disease symptoms. A comparison group for the questions of sick leave and productivity loss at work would have been beneficial. However, analysis of impact of different endometriosis-related symptoms on these two outcomes allowed for indirect conclusions on the association between endometriosis and reduced working ability, as well as basic data to design future studies.

\section{CONCLUSION}

Even if most measured effect sizes of associations between endometriosis and individual parameters of working life were small, the study indicates a burdensome influence of the disease on the working life of women affected by endometriosis. Therefore, medical and psychological support should be sensitised towards such issues in order to support women in managing their working life and adjusting their professional choices and professional development to individual endometriosis-related conditions if needed. Furthermore, for professionals in occupational medicine, insurance or politics, it might be useful to know about endometriosis-related challenges and possible limitations in professional activity.

\section{Author affiliations}

${ }^{1}$ Department of Reproductive Endocrinology, University Hospital Zurich, Zurich, Switzerland

${ }^{2}$ Department of Gynaecology and Obstetrics, Canton Hospital Schaffhausen, Schaffhausen, Switzerland

${ }^{3}$ Department of Applied Psychology, Zurich University of Applied Sciences, Zurich, Switzerland

${ }^{4}$ Division of Gynecological Endocrinology and Reproductive Medicine, University Women's Hospital, Bern, Switzerland

${ }^{5}$ Department of Psychosomatics, Charité Berlin, Berlin, Germany

${ }^{6}$ Department of Gynaecology, Endocrinology and Reproductive Medicine, Medical University Graz, Graz, Austria

${ }^{7}$ Department of Gynaecology and Obstetrics, Canton Hospital St. Gallen, St. Gallen, Switzerland

${ }^{8}$ Department of Gynecology and Obstetrics, Triemli Hospital Zurich, Zurich, Switzerland

${ }^{9}$ Department of Gynecology and Obstetrics, Canton Hospital Solothurn, Solothurn, UK

${ }^{10}$ Department of Gynaecology, University Hospital Zurich, Zurich, Switzerland

Acknowledgements We thank all participating women for supporting our study. We gratefully acknowledge the support of Brigitte Alvera, Valerie Bernays, Theodosia Charpidou, Anna Dietlicher, Franziska Graf, Franka Grischott, Elvira Gross, Nicole Kuenzle, Judith Kurmann, Christina Liebermann, Ilona Lukas, Elena Lupi, Sarah Schaerer, Karoline Stojanov and the self-help groups in data collection. We thank Salome Looser Ott, PhD, and Kathryn Imboden for critical linguistic revision of the manuscript.

Contributors MLS: collection of data on site in Solothurn and Schaffhausen, interpretation of data, drafting and finalisation of the manuscript. MPH: statistical analysis, interpretation of data, finalisation of manuscript. AKS: investigator, collection of data on site in Winterthur, Switzerland, verification of surgical reports, finalisation of the manuscript. KG: concept of study, collection of data on site in Zurich, management databank, finalisation of the manuscript. MR: investigator, collection of data on site in Berlin, Germany, finalisation of the manuscript. MMW: investigator, collection of data on site in Aachen, Germany, and in Graz, Austria, finalisation of the manuscript. FH: investigator, collection of data on site in St. Gallen, Switzerland, finalisation of the manuscript. Sv0: investigator, collection of data on site in Zurich, Switzerland, finalisation of the manuscript. ME: investigator, collection of data on site in Schaffhausen, Switzerland, finalisation of the manuscript. FM: concept of study, investigator on site in Solothurn, Switzerland, finalisation of manuscript. Bl: concept of study, investigator on site in Zurich, Switzerland, interpretation of data, finalisation of manuscript. Pl: concept of study, investigator and data collection in Zurich, Switzerland, finalisation of the manuscript. BL: principal investigator, concept and conduct of study, investigator on site in Zurich, Switzerland, collection and analysis of data, preparation and finalisation of manuscript.

Funding The authors have not declared a specific grant for this research from any funding agency in the public, commercial or not-for-profit sectors.

Competing interests None declared.

Patient consent Obtained. 
Ethics approval Cantonal Ethics Committee Zurich, St Gallen, etc.

Provenance and peer review Not commissioned; externally peer reviewed.

Data sharing statement The data set is available on request from the corresponding author.

Open access This is an open access article distributed in accordance with the Creative Commons Attribution Non Commercial (CC BY-NC 4.0) license, which permits others to distribute, remix, adapt, build upon this work non-commercially, and license their derivative works on different terms, provided the original work is properly cited, appropriate credit is given, any changes made indicated, and the use is non-commercial. See: http://creativecommons.org/licenses/by-nc/4.0/.

\section{REFERENCES}

1. Kennedy S, Bergqvist A, Chapron C, et al. ESHRE guideline for the diagnosis and treatment of endometriosis. Hum Reprod 2005;20:2698-704

2. Olive DL, Schwartz LB. Endometriosis. N Engl J Med Overseas Ed 1993;328:1759-69.

3. Acién P, Velasco I. Endometriosis: a disease that remains enigmatic. ISRN Obstet Gynecol 2013;2013:1-12.

4. Borghese B, Santulli P, Marcellin L, et al. Définition, description, formes anatomo-cliniques, pathogenèse et histoire naturelle de I'endométriose, RPC Endométriose CNGOF-HAS. / [Definition, description, clinicopathological features, pathogenesis and natural history of endometriosis: CNGOF-HAS Endometriosis Guidelines]. Gynecol Obstet Fertil Senol 2018;46:156-67.

5. Berkley KJ, Rapkin AJ, Papka RE. The pains of endometriosis. Science 2005;308:1587-9.

6. Hansen KE, Kesmodel US, Baldursson EB, et al. Visceral syndrome in endometriosis patients. Eur J Obstet Gynecol Reprod Biol 2014:179:198-203.

7. Ramin-Wright A, Kohl Schwartz AS, Geraedts K, et al. Fatigue - a symptom in endometriosis. Hum Reprod 2018:1459-65.

8. Leeners B, Damaso F, Ochsenbein-Kölble N, et al. The effect of pregnancy on endometriosis-facts or fiction? Hum Reprod Update 2018;24:290-9.

9. Kohl Schwartz AS, Gross E, Geraedts K, et al. The use of home remedies and complementary health approaches in endometriosis. Reprod Biomed Online 2018.

10. Husby GK, Haugen RS, Moen MH. Diagnostic delay in women with pain and endometriosis. Acta Obstet Gynecol Scand 2003;82:649-53.

11. Matsuzaki S, Canis M, Pouly JL, et al. Relationship between delay of surgical diagnosis and severity of disease in patients with symptomatic deep infiltrating endometriosis. Fertil Steril 2006;86:1314-6.

12. De Graaff AA, D'Hooghe TM, Dunselman GA, et al. The significant effect of endometriosis on physical, mental and social wellbeing: results from an international cross-sectional survey. Hum Reprod 2013;28:2677-85.

13. Fourquet J, Báez L, Figueroa M, et al. Quantification of the impact of endometriosis symptoms on health-related quality of life and work productivity. Fertil Steril 2011;96:107-12.

14. Nnoaham KE, Hummelshoj L, Webster P, et al. Impact of endometriosis on quality of life and work productivity: a multicenter study across ten countries. Fertil Steril 2011;96:366-73.

15. Jia SZ, Leng JH, Shi JH, et al. Health-related quality of life in women with endometriosis: a systematic review. J Ovarian Res 2012;5:29.

16. Weinstein K. The emotional aspects of endometriosis: what the patient expects from her doctor. Clin Obstet Gynecol 1988;31:866-73.

17. Fagervold $B$, Jenssen $M$, Hummelshoj $L$, et al. Life after a diagnosis with endometriosis - a 15 years follow-up study. Acta Obstet Gynecol Scand 2009;88:914-9.

18. Cummins RA. Assessing quality of life. In: Quality of life for people with disabilities: models, research and practice. , 1997:2, 116-50.

19. Simoens S, Dunselman G, Dirksen C, et al. The burden of endometriosis: costs and quality of life of women with endometriosis and treated in referral centres. Hum Reprod 2012;27:1292-9.

20. Klein S, D'Hooghe T, Meuleman C, et al. What is the societal burden of endometriosis-associated symptoms? a prospective Belgian study. Reprod Biomed Online 2014;28:116-24.

21. Aronsson G, Göransson S. Permanent employment but not in a preferred occupation: psychological and medical aspects, research implications. J Occup Health Psychol 1999;4:152-63.
22. Leeners B, Imthurn B. Psychosomatic aspects of endometriosiscurrent state of scientific knowledge and clinical experience. Gynakol Geburtshilfliche Rundsch 2007;47:132-9.

23. Denny E. Women's experience of endometriosis. J Adv Nurs 2004;46:641-8.

24. Gilmour JA, Huntington A, Wilson HV. The impact of endometriosis on work and social participation. Int J Nurs Pract 2008;14:443-8.

25. Culley L, Law C, Hudson N, et al. The social and psychological impact of endometriosis on women's lives: a critical narrative review. Hum Reprod Update 2013;19:625-39.

26. Lemaire GS. More than just menstrual cramps: symptoms and uncertainty among women with endometriosis. J Obstet Gynecol Neonatal Nurs 2004;33:71-9.

27. Huntington A, Gilmour JA. A life shaped by pain: women and endometriosis. J Clin Nurs 2005;14:1124-32.

28. von Elm E, Altman DG, Egger M, et al. The Strengthening the Reporting of Observational Studies in Epidemiology (STROBE) Statement: guidelines for reporting observational studies. Int J Surg 2014;12:1495-9.

29. Hämmerli S, Kohl Schwartz AS, Geraedts K, et al. Does endometriosis affect sexual activity and satisfaction of the man partner? A comparison of partners from women diagnosed with endometriosis and controls. J Sex Med 2018;15:853-65.

30. Liebermann C, Kohl Schwartz AS, Charpidou T, et al. Maltreatment during childhood: a risk factor for the development of endometriosis? Hum Reprod 2018:1449-58.

31. Kohl Schwartz AS, Wölfler MM, Mitter V, et al. Endometriosis, especially mild disease: a risk factor for miscarriages. Fertil Steril 2017; 108:806-14.

32. Tan G, Jensen MP, Thornby JI, et al. Validation of the brief pain inventory for chronic nonmalignant pain. J Pain 2004;5:133-7.

33. Tait RC, Chibnall JT, Krause S. The pain disability index: psychometric properties. Pain 1990;40:171-82.

34. Gronblad M. Intercorrelation and test - retest reliability of the Pain Disability Index (PDI) and the Oswestry Disability. Clin J Pain 1993;9:189-95.

35. Reilly MC, Zbrozek AS, Dukes EM. The validity and reproducibility of a work productivity and activity impairment instrument. Pharmacoeconomics 1993;4:353-65.

36. Hauser RM, Carr D. Measuring poverty and socioeconomic status in studies of health and well-being. CDE Work Pap 1995:94-24.

37. Haas D, Shebl O, Shamiyeh A, et al. The rASRM score and the Enzian classification for endometriosis: their strengths and weaknesses. Acta Obstet Gynecol Scand 2013;92:3-7.

38. Hadfield R, Mardon H, Barlow D, et al. Delay in the diagnosis of endometriosis: a survey of women from the USA and the UK. Hum Reprod 1996;11:878-80.

39. Arruda MS, Petta CA, Abrão MS, et al. Time elapsed from onset of symptoms to diagnosis of endometriosis in a cohort study of Brazilian women. Hum Reprod 2003;18:756-9.

40. Greene R, Stratton P, Cleary SD, et al. Diagnostic experience among 4,334 women reporting surgically diagnosed endometriosis. Fertil Steril 2009;91:32-9.

41. Fourquet J, Gao X, Zavala D, et al. Patients' report on how endometriosis affects health, work, and daily life. Fertil Steril 2010:93:2424-8.

42. Brosens I, Gordts S, Benagiano G. Endometriosis in adolescents is a hidden, progressive and severe disease that deserves attention, not just compassion. Hum Reprod 2013;28:2026-31.

43. Dovey S, Sanfilippo J. Endometriosis and the adolescent. Clin Obstet Gynecol 2010;53:420-8.

44. Petrelluzzi KF, Garcia MC, Petta CA, et al. Salivary cortisol concentrations, stress and quality of life in women with endometriosis and chronic pelvic pain. Stress 2008;11:390-7.

45. Siedentopf F, Tariverdian N, Rücke M, et al. Immune status, psychosocial distress and reduced quality of life in infertile patients with endometriosis. Am J Reprod Immunol 2008;60:449-61.

46. de Vries HJ, Brouwer S, Groothoff JW, et al. Staying at work with chronic nonspecific musculoskeletal pain: a qualitative study of workers' experiences. BMC Musculoskelet Disord 2011;12:1.

47. Burton WN, Conti DJ, Chen CY, et al. The economic burden of lost productivity due to migraine headache: a specific worksite analysis. $J$ Occup Environ Med 2002;44:523-9.

48. McDonald M, DiBonaventura M, Ullman S. Musculoskeletal pain in the workforce: the effects of back, arthritis, and fibromyalgia pain on quality of life and work productivity. J Occup Environ Med 2011;53:765-70.

49. Sinaii N, Cleary SD, Ballweg ML, et al. High rates of autoimmune and endocrine disorders, fibromyalgia, chronic fatigue syndrome and atopic diseases among women with endometriosis: a survey analysis. Hum Reprod 2002;17:2715-24. 